\title{
Injectable bulking agents for passive faecal incontinence
}

\author{
C. E. Koh • M. J. Solomon
}

Received: 11 April 2013/Accepted: 13 April 2013/Published online: 9 May 2013

(C) Springer-Verlag Italia 2013

Faecal incontinence (FI) is a socially isolating condition that can adversely impact upon one's quality of life [1]. Depending on the definitions used, the population surveyed and the method of reporting, between 2 and $24 \%$ of the population has some degree of FI [2]. Incontinence caused by deficiencies of the internal sphincter, regardless of the underlying cause, is characterized by reduced resting pressures and passive incontinence [3]. Unfortunately, there is little targeted therapy available for this type of incontinence $[4,5]$. Aside from anti-diarrhoeals and biofeedback which form the backbone of conservative management, the only other available options are either complex or major surgery, such as sacral nerve stimulation, artificial bowel sphincter implantation or the formation of a permanent colostomy [4, 6]. The use of injectable bulking agents, a safe and minimally invasive procedure that seems to be effective at least in the short term, is therefore inherently attractive as it fills the wide chasm between conservative and surgical management of FI.

Bulking agents were first adopted for use in FI in 1993 following successes in the treatment of stress urinary incontinence. The mechanism by which they work is to augment the internal sphincter where it is deficient thereby facilitating anal canal closure. To date, at least 10 different agents have been described using different routes (transanal, transsphincteric, intersphincteric) to deposit the biomaterial at different sites (submucosa, intersphincteric, directly into the internal sphincter) [7].

This issue of the journal features a small randomized controlled trial by Morris et al. [8] comparing two

C. E. Koh $(\varangle) \cdot$ M. J. Solomon

Surgical Outcomes Research Centre, Royal Prince Alfred

Hospital, Sydney, NSW, Australia

e-mail: cherry_koh@hotmail.com injectable bulking agents. The authors have to be applauded for their efforts considering the paucity of randomized trials on the subject and demonstration of a positive result despite unforeseen problems with product withdrawal by the Pharmaceutical Benefits Scheme (the medication approval agency of Australia) which led to premature termination of the trial. The authors demonstrated that bulking agents improved continence by at least the minimal change detectable by Wexner continence scores [9]. Encouragingly, this improvement in Wexner scores was also accompanied by a modest improvement in resting pressures which would lend weight to treatment efficacy by bulking agents [8]. However, in the absence of a control arm to answer pertinent questions about treatment efficacy, this study is in a way similar to all the other published case series.

Although conceptually attractive, its efficacy and its durability, if there is indeed a benefit, are both questionable. In a recent Cochrane review by Maeda et al. [4], only 5 randomized controlled trials could be identified. Further, although the pooled number of patients was 382 , most (206) were derived from the recent placebo controlled trial by Graf et al. [10]. Of the 5 trials, only two have assessed the efficacy of bulking agents against placebo $[5,10]$. The study by Siproudhis et al. [5] did not demonstrate a difference between $\mathrm{PTQ}^{\mathrm{TM}}$ (Uroplasty BV, Geleen, The Netherlands) and placebo (77 and $72 \%$ response rates, respectively), and while the study by Graf et al. [10] reported greater improvements in the treatment arm (53 vs. $32 \%$ ), there was a considerable placebo effect in the control arm. Pooled analysis of observational studies, however, would suggest that bulking agents are more effective than they actually are. In the review by Hussain et al. [7], pooled analysis of case series found that $70 \%$ of patients treated reported a positive treatment response of 
which $56 \%$ were classified as good response and $13 \%$ as having achieved complete continence.

In order to provide objective evidence of improvement, some studies have looked at the effect of bulking agents on resting and squeeze pressures [11, 12]. Tjandra et al. [11] reported a clinically and statistically significant increase in the maximum resting pressures at 3 months after treatment (23-38 mmHg), whereas Altomare et al. [12] reported significant increases in both resting $(34-42 \mathrm{mmHg}$ ) and squeeze pressures $(66-79 \mathrm{mmHg})$. However, it is also important to highlight that many others have not been able to demonstrate corroborative increases in anal pressures to support the improvements in continence scores or quality of life [13].

In terms of durability, few studies have reported longterm outcomes [7, 13]. Most studies seem to suggest that the benefits of bulking agents appear to dissipate by 6-12 months, including the current study by Morris et al. [8]. Loss of treatment efficacy is likely to be related to migration of the bulking agent. In a study by Maeda et al. [14], 9 of 10 patients had evidence of agent dissipation on a repeat endoanal ultrasound performed just 6 weeks after injection. More interestingly, despite deterioration of continence back to pre-treatment levels, quality of life improvement seems more sustained, which again suggests that it is the care and medical attention received that might be responsible for the sense of well-being rather than treatment efficacy [15].

Whether or not treatment efficacy is affected by the use of different agents is also currently unclear. To date, three studies have compared treatment outcomes between different agents. The current study by Morris et al. [8] and the one by Tjandra et al. [11] compared $\mathrm{PTQ}^{\mathrm{TM}}$ and Durasphere $^{\mathrm{TM}}$ (pyrolytic carbon-coated beads, Carbon Medical Technologies Inc, Minnesota, United States of America), whereas the study by Maeda et al. [14] compared Bulkamid $^{\mathrm{TM}}$ (hydrogel cross-linked with polyacrylamide, Contura, Soeborg, Denmark) and Permacol ${ }^{\mathrm{TM}}$ (porcine dermal collagen, Tissue Science Laboratories, Covington, Georgia, United States of America), Of these, the only study to suggest that one agent is superior to the other was the Tjandra study which reported that more patients who received $\mathrm{PTQ}^{\mathrm{TM}}$ had $>50 \%$ reduction in incontinence scores compared to those who received Durasphere ${ }^{\mathrm{TM}}$ [11]. However, there is inadequate data at present to support the use of one agent rather than the other.

In conclusion, evidence on bulking agents is relatively scant. There is at least one large randomized trial that would support the use of bulking agents prior to consideration of more invasive surgical options [10]. Although bulking agents are unlikely to be durable in the long term, they may be a reasonable short- to medium-term solution. Bulking agents are safe, minimally invasive, and importantly, they do not preclude future surgical options should treatment fail. Their role in the treatment algorithm of faecal incontinence continues to evolve but for now, they "plug" the gap between conservative and complex surgical options.

Conflict of interest None.

\section{References}

1. Parés D, Vial M, Bohle B et al (2011) Prevalence of faecal incontinence and analysis of its impact on quality of life and mental health. Colorectal Dis 13:899-905

2. Macmillan AK, Merrie AE, Marshall RJ, Parry BR (2004) The prevalence of fecal incontinence in community-dwelling adults: a systematic review of the literature. Dis Colon Rectum 47:1341-1349

3. Rao S (2004) Pathophysiology of adult fecal incontinence. Gastroenterol 126(Suppl 1):S14-S22

4. Maeda Y, Laurberg S, Norton C (2013) Perianal injectable bulking agents as treatment for faecal incontinence in adults. Cochrane Database Syst Rev. doi:10.1002/14651858

5. Siproudhis L, Morcet J, Laine F (2007) Elastomer implants in faecal incontinence: a blind, randomized placebo-controlled study. Aliment Pharmacol Ther 25:1125-1132

6. Chatoor D, Taylor S, Cohen C, Emmanuel A (2007) Faecal incontinence. Br J Surg 94:134-144

7. Hussain Z, Lim M, Stojkovic S (2011) Systematic review of perianal implants in the treatment of faecal incontinence. Br J Surg 98:1526-1536

8. Morris O, Smith S, Draganic B (2013) Comparison of bulking agents in the treatment of fecal incontinence: a prospective randomized clinical trial. Tech Coloproctol. doi:10.1007/s10151013-1000-4

9. Bols E, Hendriks E, Berghmans B, Baeten C, de Bie R (2013) Responsiveness and interpretability of incontinence severity scores and FIQL in patients with fecal incontinence: a secondary analysis from a randomized controlled trial. Int Urologynaecol J 24:469-478

10. Graf W, Mellgren A, Matzel K, Hull T, Johansson C, Bernstein M, NASHA Dx Study Group (2011) Efficacy of dextranomer in stabilised hyaluronic acid for treatment of faecal incontinence: a randomised, sham-controlled trial. Lancet 377:997-1003

11. Tjandra J, Lim J, Hiscock R, Rajendra P (2004) Injectable silicone biomaterial for fecal incontinence caused by internal anal sphincter dysfunction is effective. Dis Colon Rectum 47: $2138-2146$

12. Altomare D, La Torre F, Rinaldi M, Binda G, Pescatori M (2008) Carbon-coated microbeads anal injection in outpatient treatment of minor fecal incontinence. Dis Colon Rectum 51:432-435

13. Luo C, Samaranayake C, Plank L, Bissett I (2010) Systematic review on the efficacy and safety of injectable bulking agents for passive faecal incontinence. Colorectal Dis 12:296-303

14. Maeda Y, Vaizey C, Kamm M (2008) Pilot study of two new injectable bulking agents for the treatment of faecal incontinence. Colorectal Dis 10:268-272

15. Maeda Y, Vaizey C, Kamm M (2007) Long term results of perianal silicone injection for faecal incontinence. Colorectal Dis 9:357-361 